\title{
Peluang Kerja Penyandang Disabilitas di Kota Metro
}

\author{
Aisyah Sunarwan \\ Institut Agama Islam Negeri Metro, Indonesia
}

aisyahsunarwan@gmail.com*

\begin{tabular}{|c|c|}
\hline & Abstract \\
\hline $\begin{array}{c}\text { ARTICLE INFO } \\
\text { Article history: } \\
\text { Received } \\
\text { October 01, 2021 } \\
\text { Revised } \\
\text { November 01, } \\
2021 \\
\text { Accepted } \\
\text { December 29, } \\
2021\end{array}$ & $\begin{array}{l}\text { Getting a job is something that everyone really wants without exception for } \\
\text { people with physical disabilities. In Metro, there are many people with physical } \\
\text { disabilities who do not or have not gotten a job so they do anything to survive. } \\
\text { This study was conducted to determine employment opportunities for people } \\
\text { with physical disabilities based on the Law of the Republic of Indonesia Number } \\
8 \text { of } 2016 \text { article } 53 \text {. Data in this study were obtained through observation and } \\
\text { interview process to the heads of agencies and people with physical disabilities } \\
\text { in Metro. Based on the results of the analysis of the data obtained, it can be } \\
\text { concluded that the job opportunities for persons with physical Disabilities in } \\
\text { Metro are still relatively low and the rights to obtain employment for persons } \\
\text { with disabilities as stipulated in the Act are still not well realized. }\end{array}$ \\
\hline & Keywords: first keyword, second keyword, third keyword \\
\hline Published by & $\begin{array}{l}\text { Lembaga Penelitian dan Pengabdian Kepada Masyarakat } \\
\text { Institut Agama Islam Negeri Metro }\end{array}$ \\
\hline Website & http://e-journal.metrouniv.ac.id/index.php/tapis/index \\
\hline \multicolumn{2}{|c|}{$\begin{array}{l}\text { This is an open access article under the CC BY SA license } \\
\text { https://creativecommons.org/licenses/by-sa/4.0/ }\end{array}$} \\
\hline
\end{tabular}

\section{PENDAHULUAN}

Usaha pelayanan terhadap penyandang disabilitas kerap dilakukan oleh pemerintah serta berbagai kalangan di masyarakat. Sebuah bentuk empati dalam rangka pemenuhan atas hak pendidikan dan kesejahteraan sosial. Hak mendasar yang secara kodrati dapat dimilik oleh setiap warga Negara adalah hak Asasi Manusia. Selain itu, hak penyandang Disabilitas yang juga diatur dalam UUD NKRI Tahun 1945, yaitu memperjuangkan haknya secara kolektif dalam pembangunan Bangsa dan Negara (Pasal 28C ayat 2) yang bebas dari penyiksaan atau perlakuan merendahkan derajat dan martabat serta bebas dari perlakuan diskriminatif atas dasar apapun. Hal tersebut kemudian diperjelas dengan peraturan pasal $28 \mathrm{D}$ ayat (2) yang menjelaskan "bahwa setiap orang berhak untuk bekerja serta mendapatkan imbalan dan perlakuan yang adil dan layak dalam hubungan kerja. Hak asasi dari setiap warga Negara ini kemudian sejalan dengan adanya kewajiban pemerintah yang tertuang dalam Pasal 281 bahwa perlindungan, pemajuan, penegakan, dan pemenuhan hak asasi adalah tanggungjawab negara terutama pemerintah. Dengan demikian jelaslah bahwa keberadaan penyandang disabilitas harus mendapatkan jaminan dari pemerintah.

Pada Undang-Undang Republik Indonesia Nomor 8 Tahun 2016 pasal 53, disebutkan bahwa lembaga pemerintahan, BUMN, maupun BUMD memiliki kuota minimal mempekerjakan $2 \%$ tenaaga penyandang disabilitas, sedangkan perusahaan swasta minimal mempekerjakan tenaga kerja penyandang disabilitas sebanyak $1 \%$ untuk mendapatkan pekerjaan yang akan memberi kontribusi, baik pada tingkat individu penyandang disabilitas itu sendiri dalam bentuk kehidupan yang lebih produktif. Hal ini menunjukan bahwa Pemerintah pusat dan Pemerintah Daerah wajib menjamin proses rekrutmen, penerimaan, pelatihan kerja, penempatan kerja, keberlanjutan kerja, dan pengembangan karier yang adil dan tanpa diskriminasi kepada penyandang disabilitas. 
Menurut data statistik terakhir yang dilakukan oleh Badan Pusat Statistik Provinsi Lampung pada tanggal 26 Agustus 2015, jumlah penyandang disabilitas yang ada di Lampung Mencapai 23.000 Jiwa. Sementara pada tahun 2018 ini ada sekitar 1.666 penyandang disabilitas yang masih berstatus pelajar dan mengikuti pendidikan di 25 SLB di Provinsi Lampung.

Di Kota Metro ini misalnya, terdapat lebih dari 50 penyandang disabilitas yang telah lulus pendidikan jenjang SMA tidak memiliki pekerjaan tetap dikarenakan tidak semua tempat atau perusahaan yang mau menerima karyawan dengan keterbatasan dan hambatan penyandang disabilitas. Situasi seperti ini yang menyebabkan mereka melakukan berbagai usaha demi kelangsungan hidup, mulai dari menjaga warung, berjualan Koran dan lain sebagainya yang hasilnya tentu tetap belum mencukupi kebutuhan pokok mereka.

Kondisi yang terjadi kemudian membuat peneliti tertarik untuk melakukan penelitian dengan melakukan observasi terlebih dahulu mengenai keberadaan dan pekerjaan mereka di Kota Metro. Pada dasarnya para penyandang disabilitas telah dibekali keterampilan dari tempat mereka bersekolah. Contoh keterampilan bagi penyandang tuna rungu siswa lulusan SLB Wiyata Dharma dibekali keterampilan membatik dan membuat sandal. Bekal keterampilan yang telah dimiliki ternyata belum cukup untuk menunjang kebutuhan mereka, karena terbukti mereka harus pula melakukan pekerjaan lain demi keberlangsungan hidup yang lebih layak.

Potensi yang ada pada penyandang disabilitas seharusnya dapat dikembangkan lebih baik lagi dengan mempertimbangkan jenis pekerjaan yang dapat dilakukan oleh penyandang Disabilitas. Pekerjaan sebagai Office Boy pada suatu perusahaan mungkin saja dapat menjadi alternative bagi mereka.

Penelitian ini menggambarkan seberapa besar peluang para penyandang disabilitas memperoleh pekerjaan yang lebih layak untuk memenuhi kebutuhan hidup, mengingat bahwa setiap orang memiliki kesempatan dan hak yang sama dalam mendapatkan pekerjaan dan kesuksesan.

\section{METODE}

Penelitian ini adalah Penelitian deskriptif bermaksud mendeskripsikan atau menggambarkan secara detail fenomena yang terjadi di Kota Metro mengenai hak pekerjaan penyandang disabilitas, sehingga dapat diketahui akar pokok permasalahan yang dikaji, sekaligus menyajikan solusi sesuai dengan sifat masalah yang dihadapi. Pengumpulan data teoritik dilakukan melalui studi pustaka (library research). Pengumpulan data empirik menggunakan teknik berikut teknik Indepth Interview (wawancara mendalam) yaitu memperoleh data secara langsung melalui dialog mendalam berkenaan dengan peluang kerja penyandang disabilitas di Kota Metro kepada pimpinan Instansi dan penyandang disabilitas. Selain itu, Observasi juga dilakukan dengan mengungkap fenomena berkaitan dengan hak-hak penyandang disabilitas di Kota Metro, terutama hak mendapatkan pekerjaan dan kesejahteraan sosial.

Triangulasi yang digunakan sebagai validitas data adalah triangulasi sumber yaitu membandingkan data wawancara dengan hasil observasi atau isi suatu dokumen, melakukan cross check kepada atasan atau bawah, atau partner narasumber terkait mengenai benar atau tidaknya data yang telah didapatkan. Data yang telah diperoleh kemudian dianalisis dengan menggunakan metode deskriptif-interpretatif dengan memberikan penafsiran atau interpretasi peranan proses berfikir dari peneliti yang secara umum harus bersifat rasional, kritis, analitik, sintetik dan logis dengan melakukan: 1) identifikasi fenomena yang diteliti, 2) identifikasi sasaran dalam penelitian, 3) generasi hipotesis, 4) pengumpulan data, 5) analisis data dan interpretasi, dan 6) kesimpulan.

\section{HASIL DAN PEMBAHASAN}

Penyajian hasil penelitian untuk mengetahui peluang kerja penyandang disabilitas di Kota Metro dilakukan dengan mendeskripsikan data yang diperoleh melalui wawancara yang dilaksanakan dengan Pimpinan Instansi Pemerintah dan penyandang disabilitas di kota Metro. Data yang disajikan pada penelitian ini diperoleh melalui wawancara yang dilakukan kepada 
beberapa pimpinan instansi yang berada di kota Metro, diantaranya; 1) Ibu Siti Aisyah sebagai kepala Dinas Koperasi, 2) Ibu Ria Andari sebagai kepala Dinas Pendidikan dan Kebudayaan Kota metro, 3) Ibu Rachmayani sebagai Kepala Pukesmas Iringmulyo Metro timur, 4) Ibu Yuli Hartati Sebagai Kepala Sekolah SLB Negeri Metro, 5) Ibu Ika Yuniarti Kasubdit Kesejahteraan sosial dan Kebudayaan BAPPEDA, 6) Bapak Subehi Sebagai Sekretaris Dinas sosial Kota Metro. Adapun hasil wawancara kepada pimpinan-pimpinan instansi diatas disampaikan sebagai berikut:

Dari hasil wawancara yang telah dilakukan dengan pimpinan Instansi, terdapat beberapa kemiripanan jawaban meskipun tidak sama persis. Kesamaan itu tampak pada sikap dan respon dari pihak instansi yang belum mengetahui bahwa terdapat undang-undang yang mengatur tentang hak para penyandang disabilitas untuk dapat memperoleh pekerjaan pada suatu instansi. Pada dasarnya mereka menerima keberadaan para penyandang disabilitias di lingkungan kerja yang mereka pimpin dengan segala kemampuan mereka selama para penyandang disabilitas dapat melakukan pekerjaannya dengan baik. Seperti Puskesmas Iringmulyo Metro Timur misalnya, telah mempekerjakan penyandang disabilitas dengan hambatan bicara yaitu Mulyono. Pihak Puskesmas memperhatikan Mulyono sebagai sosok yang ini rajin karena beberapa kali dipanggil untuk membersihkan rumput, merapihkan tanaman, dan membersihkan halaman puskesmas dengan hasil yang memuaskan. Dengan pertimbangan tersebut akhirnya pimpinan Puskesmas untuk merekrut Mulyono sebagai karyawan dari Puskesmas Iringmulyo sebagai Cleaning Service.

Sejauh ini pihak Puskesmas tidak membatasi siapapun untuk mengajukan lamaran pekerjaan tetapi karena memang sehat jasmani dan rohani ini selalu menjadi persyaratan yang telah ditentukan sehingga mungkin hal ini menyebabkan belum pernah ada pelamar disabilitas. Beliau juga menyampaikan beberapa contoh pekerjaan lain yang mungkin dapat dikerjakan oleh penyandang disabilitas. seseorang yang harus beraktifitas dengan kursi Roda karena hambatan yang dimiliknya mungkin saja dipekerjakan pada bidang keahlian yang fokus dengan computer selama orang tersebut menguasai ilmu komputer. Selain itu, posisi sebagai pembantu rumah tangga sangat mungkin dilakukan oleh tuna rungu. Mereka akan tetap terampil melakukan pekerjaan seperti menyiapkan air minum untuk para pegawai, mempersiapkan konsumsi jika terdapat acara kantor, dan bertanggungjawab menjaga dapur agar tetap selalu bersih. Kendala mengenai persyaratan sehat fisik dan mental ini yang kemudian seolah menjadi batasan bahwa lowongan tersebut hanya untuk para penyandang disabilitas.

Di kesempatan lain, Ibu siti Aisyah selaku Kepala Dinas Koperasi dan UMKM kota Metro menyampaikan bahwa terdapat penyandang disabilitas di instansi yang beliau pimpin yaitu Heru yang mampu menyelesaikan pekerjaannya dengan baik. Hanya beberapa kendala saja saat mengerjakan tugas lewat komputer. Saat ditanya soal hak-hak penyandang disabilitas yang tertuang dalam UU PD nomor 08 tahun 2016, beliau menyatakan pernah mengikuti Forum Group Discussion tentang hal tersebut di SLB Wiyata Dharma Metro. Hal itulah yang menyebabkan dinas untuk tetap mempertahankan Heru sebagai karyawan kontrak. Dalam wawancara tersebut beliau menyarankan agar berkoordinasi dengan dinas tenaga kerja terkait dengan pemenuhan hak-hak penyandang disabilitas dalam memperoleh pekerjaan. Selain itu dalam konteks memerhatikan penyandang disabilitas, Dinas Koperasi dan UMKM melakukan pelatihan usaha mikro, kecil dan menengah bagi mereka dan membantu proses pemasarannya. Bahkan dengan berkoordinasi dengan pemerintah Kota Metro memiliki kerjasama dengan beberapa swalayan untuk pemasarannya.

Terkait dukungan mengenai para penyandang disabilitas, kepala Dinas Koperasi meyampaikan bahwa bisa saja mereka menerima lebih dari satu penyandang disabilitas di tempatnya selama aturan dari pemerintah itu jelas dan terstruktur mengenai lowongan pekerjaan untuk umum dan khusus bagi para penyandang diasbilitas memiliki syarat dan ketentuan yang tidak dapat disamakan dengan pelamar umum. Misalnya dibuka lowongan pekerjaan Kepala Dapur bagi penyandang disabilitas dengan ketentuan hambatan pendengaran, sehingga amanat undang-undang dapat diterapkan dengan baik. 
Pada instansi lain, yaitu SLB Negeri Kota Metro, berdasarkan penuturan dari Ibu Yuli Haratati, Ada 6 penyandang disabilitas yang bekerja sebagai staff administrasi dan kebersihan. Ibu Yuli mengungkapkan alasan untuk menerima mereka karena amanat undang-undang selain aspek kemanusiaan. Secara administratif mereka mendapatkan SK dari kepala sekolah. Saat ditanya mengenai insentif bulanan, beliau menuturkan bahwa pada saat ini belum mampu untuk menyesuaikan dengan Upah Minimum Regional (UMR). Namun demikian setidaknya SLB Negeri Kota Metro sudah berusaha untuk memenuhi hak-hak penyandang disabilitas.

Wawancara kemudian dilanjutkan kepada Ibu Ika Yuniarti sebagai Kasubbid Kesejahteraan Sosial dan Pemberdayaan BAPPEDA Kota Metro. Beliau meyampaikan bahwa belum ada pegawai dengan penyandang disabilitas di BAPPEDA. Selama ini memang belum pernah membuka lowongan yang dikhususkan untuk para penyandang disabilitas. Beliau juga menuturkan bahwa belum pernah ada sosialisasi mengenai kewajiban instansi dalam mempekerjakan para penyandang disabilitas dari pemerintah daerah yang dengan hal ini diyakini bahwa instansi lain juga kemungkinan besar mengalami hal yang sama. Meskipun belum ada pegawai disabilitas tetapi instansi BAPPEDA telah menerapkan gedung yang ramah akan penyandang disabilitas. Hal ini dibuktikan dengan adanya tangga yang landai dapat diakses oleh para penyandang disabilitas.

Wawancara yang terakhir adalah wawancara yang dilakukan kepada Sekretaris Dinas sosial yaitu Bapak Subehi. Ketika diwawancarai terkait ada atau tidaknya pegawai yang berkebutuhan khusus, beliau menyampaikan tidak ada karena memang pihak Dinsos belum pernah membuka lowongan pekerjaan yang khusus bagi penyandang disabilitas. Meskipun demikian, pihak dinas telah berupaya membantu para penyandang disabilitas dengan memberikan sosialisasi tentang beberapa kegiatan atau aktifitas yang dapat dilakukan oleh mereka untuk kemudian dapat menghasilkan uang. Soaisalisai yang pernah dilakukan diantaranya, pelatihan membuat sulam usus bagi para penyandang disabilitas wanita, pelatihan mekanik atau perbengkelan bagi mereka yang berminat pada bidang ini, mereka dapat megetahui permasalahan yang sering terjadi pada kendaraan bermotor dan memperbaikinya. Bagi tuna netra, disediakan pelatihan pijat, dimana para penyandang disabilitas dapat melatih kemampuan mereka untuk melancarkan peredaran darah. Semua kegiatan sosialisasi dan pelatihan diatas bertujuan agar para penyandang disabilitas dapat lebih mandiri dan bekerja sesuai dengan kemampuan mereka dengan membuka usaha sendiri. Tidak hanya itu, Dinas Sosial juga memberikan bantuan berupa gerobak dagang yang dapat dimanfaatkan, kemudian bantuan berupa paket alat musik juga pernah diberikan kepada komunitas tuna netra di Kota Metro.

Meskipun bantuan telah dikucurkan untuk para penyandang disabilitas, tetapi tidak semua dapat berjalan dengan baik. Ketidak mampuan mereka dalam mengatur usaha mungkin menjadi salah satu penyebabnya. Banyak program yang hanya berhenti tanpa adanya tindak lanjut dari pihak pemerintah daerah dan dengan tidak efektifnya usaha yang mereka jalankan akhirnya memaksa mereka untuk kembali pada aktifitas mereka sebelumnya, yaitu kegiatan seperti mengamen di SPBU, menjual Koran, dan kegiatan lain yang pada dasarnya harus mereka hindari.

Amanat Undang-undang memang sebaiknya dilaksanakan oleh instansi yang telah ditentukan bahwa penyandang disabilitas memiliki hak untuk mendapatkan pekerjaan sebanyak $2 \%$ dari jumlah pegawai pada instansi Pemerintah, dan $1 \%$ untuk instansi swasta. Terkait hal ini, perlu adanya edaran atau sosialisasi dari pemerintah mengenai kebijakan yang telah diamanatkan melalui undang-undang tersebut dan agar semua instansi pemerintah membuka lowongan pekerjaan khusus bagi para penyandang disabilitas dengan syarat dan ketentuan yang sesuai dengan kondisi mereka.

Sedangkan wawancara dengan para penyandang disabilitas yang tersebar pada beberapa instansi dapat disimpulkan bahwa pada dasarnya mereka mampu menyelesaikan tugas utama mereka dengan baik. Mereka juga percaya diri ketika harus berkomunikasi dengan banyak orang dan tidak keberatan jika diminta untuk melakukan sesuatu atau pekerjaan yang diluar 
tugas utama mereka. Keyakinan dan ketulusan bahwa dengan menjalankan tugas sebaik-baiknya akan memberikan dampak yang baik pula terhadap mereka.

Hal yang masih dirisaukan oleh para penyandang disabilitas adalah belum semua penyandang disabilitas tidak memiliki kesempatan yang sama seperti mereka, yaitu bekerja dan diterima baik pada suatu instansi atau tempat kerja yang layak dengan penghasilan yang layak pula. Masih terdapat banyak penyandang disabilitas yang menghabiskan waktunya dengan mengamen, berjualan koran dan lain sebagainya untuk memenuhi kebutuhan hidup. Oleh karena itu diharapkan adanya sikap tegas dari pemerintah untuk mengentaskan masalah tersebut, salah satunya dengan memberikan sosialisasi kepada lembaga-lembaga pemerintahan secara umum dan lembaga swasta secara khusus tentang pentingnya memberikan ruang dan hak yang sama bagi para penyandang disabilitas sesuai dengan jenis pekerjaan dan jenis keterbatasan yang mereka miliki.

\section{KESIMPULAN}

Berdasarkan hasil penelitian dan pembahasan dapat disimpulkan bahwa peluang kerja penyandang disabilitas di Kota Metro masih tergolong rendah. Hal ini dibuktikan dengan tidak adanya formasi khusus bagi pelamar disabilitas dalam perektrutan pegawai. Hal ini terjadi karena kesehatan jasmani dan rohani menjadi salah satu syarat utama bagi para pelamar. Selain itu, hak-hak memeroleh pekerjaan bagi penyandang disabilitas yang termaktub dalam UU No.08 Tahun 2016 masih belum terealisasi dengan baik. Belum ada peraturan pemerintah yang menjelaskan teknis rekrutmen bagi pekerja penyandang disabilitas, sehingga seluruh instansi belum memiliki payung hukum pasti dalam memenuhi hak-hak penyandang disabilitas untuk memeroleh pekerjaan.

\section{UCAPAN TERIMA KASIH}

Terimakasih disampaikan kepada seluruh pihak yang telah membantu dalam penyelesaian penelitian ini terkhusus disampaikan kepada Kementrian Agama dan Institut Agama Islam Negeri Metro karena telah mendanai penelitian ini sampai dengan selesai.

\section{PERNYATAAN KONTRIBUSI PENELITI}

Penelitian ini ditulis oleh Aisyah Sunarwan dengan pendanaan dari Kementrian Agama Republik Indonesia.

\section{REFERENSI}

Arrista Trimaya, "(Ways to Respect, Protect, and Fulfill the Rights of Persons with Disabilities through Law Number 8 OF 2016" 13 (2016): 9.

Abdul LAtief Danu Aji dan Tiyas Nur Haryani, Diversitas dalam Dunia Kerja: Peluang dan Tantangan bagi Disabilitas, Spirit Publik Volume 12, Nomor 2 Oktober 2017

Apri Nuryanto, “Analisis Peluang Kerja Bidan Teknik Mesin pada Bursa kerja online,” JPTK 16 No.2 (2007).

Arif BUrhan Efendi dan Rahaditia Yunianto, Implementasi Diversity Program bagi Tenaga Kerja Penyandang DIsabilitas pada PT. Wangta Agung Kota Surabaya, UDS 2017, Vol.04 No.02, Desember 2017

Badan Pusat Statistik, “Tenaga Kerja” (Bandar lampung, 2015).

Budiono, “Teori Pertumbuhan Ekonomi” (BP FE-UGM Yogyakarta, 1982).

Devi Lestyarini, "Hubungan Upah minimum provinsi dengan jumlah tenaga kerja formal di Jawa Timur" (Fakultas Ekonomi Unesa Jawa Timur, t.t.). 
Doni Roma Dona dan Aji Sofyan Effendi, "Analisis faktor-faktor yang mempengaruhi kesempatan kerja," 2018, 7.

Fraenkel, J.R \& Wallen, N.E.2010. How to Design and Evaluate Reseach Harlow.Longman Group UK Limited. Teaching and Applied Linguistics. London: Pearson Education Limited

Harian Lampung Post Edisi Selasa 02 oktober 2018. https://lampung.bps.go.id/statictable/2015/08/06/255/banyaknya-penyandang-masalahkesejahteraan-sosial-menurut-kabupaten-kota-di-provinsi-lampung-2014.html

Kamus Besar Bahasa Indonesia Pusat Bahasa ,Edisi Ke empat, (Departemen Pendidikan Nasional: Gramedia, Jakarta,2008).

Nur Kholis Reefani, Panduan Anak Berkebutuhan Khusus, (Yogyakarta:Imperium.2013), hlm.17

Peraturan Daerah Provinsi Lampung Nomor 10 Tahun 2013 tentang Pelayanan dan Pemenuhan Hak-Hak Penyandang Disabilitas

Pramadita Hasbullah dan Rahayu, Hak asasi manusia bagi Penyandang Disabilitas dalam Mendapat Pekerjaan yang Layak tanpa adanya Diskriminasi, Hukum dan Dinamika Masyarakat vol.15, No.02, April 2018

R Wiliasih dan D.f Salsabila, "Faktor-Faktor yang Mempengaruhi Kualitas HIdup Tenaga Kerja Penyandang DIsabilitas," Jurnal Syarikah P-ISSN 2442-4420 e-ISSN 2528-6935, Volume 3 Nomor 2 (Desember 2017).

UU No 13, “Tenaga Kerja,” 2003.

Simanjuntak, Jurnal Perindustrian Indonesia (Perpustakaan Dinas Perindustrian dan Perdangan Bapan Pusat Statistik Makassar, 2000).

Sukirno, Analisis Investasi secara Makro (Yogyakarta: Gajah Mada University Press, 1990).

Suroto, Ketenagakerjaan Indonesia (Jakarta: Grafindo, 1986).

Undang-Undang No.8 Tahun 2016

Undang-Undang Dasar 1945 Pasal 28A

Undang-undang Dasar Negara Republik Indonesia Pasal 28 ayat (2)

Undang-Undang dasar 1945 Pasal 27 ayat (2)

Undang-Undang Dasar 1945 Pasal 28D

Zulfah Latuconsina, "Afirmasi Kebijakan Pemerintah dalam Fasilitasi Kerja bagi Penyandang Disabilitas," Pandecta: Research Law Journal 9, no. 2 (1 Desember 2014): 207, https://doi.org/10.15294/pandecta.v9i2.3445 


\section{Copyright Holder :}

(C) Sunarwan, A., (2021).

\section{First Publication Right :}

(C) Tapis : Jurnal Penelitian Ilmiah

This article is under:

CC BY SA 